\title{
개발원조위(DAC) 개발평가 네트워크 회의 결과
}

$\mathrm{OECD} / \mathrm{DAC}$ 산하 개발평가 네트워크(DAC Network on Development Evaluation) 제6차 회 의가 Mr. Finbar O’ Brien 의장(아일랜드) 주재로 6. $27 \sim 28$ 간 파리에서 개최되어 원조효과 공동평 가, 평가 능력 개발, 변화하는 개발원조환경과 평 가와의 관계, 평가도구 및 기준 등이 협의되었고 주요 내용은 다음과 같다.

\section{I. 핵심 요지}

- 파리 선언 모니터링을 위해, 수원국 주도의 평 가와 공여국 주도의 평가 등으로 추진중인 공 동 평가(joint evaluation) 작업에 대해 대다수 회원국들이 지지를 표명했다.

- 다만 수원국 주도의 평가에 대해서는 방글라 데시, 말리, 볼리비아 등 동 대상국(자발적 참 여)들이 $\mathrm{DAC}$ 회원국들의 주요 원조 집중국 (donor darling)인 점을 감안하여, biased된 결 과를 가져오지 않도록 하는 점이 지적되었다.

- 중국은 네덜란드와 공동으로 수원국 주도의 공동 평가 작업(84개 프로젝트 사업 대상)을 2004-2005년간 실시하여 금번회의에서 동 평가 작업을 발표하였으며, 주요 문제로는 평 가에 대한 문화적 차이와 평가결과가 중앙정 부에 반영되기 어렵다는 점이 지적되었다.

- 중국은 과기부 산하 국립과학기술평가센터 (NSSTE)가 총괄적으로 원조 평가를 담당하 고 있다.

- 지난 2006 년 4 차 회의에서 승인된 평가의 질 적 기준(Evaluation Quality Standards)에 대한 회원국의 의견을 종합하여, 동 기준 개선 및 확정을 위한 워크샵을 추후 개최키로 합의 하였다. 


\section{II. 관찰 및 평가}

- 금번 회의에서 방글라데시, 베트남, 중국, 탄 자니아 등이 참여한 공동 평가 작업에 대한 소 개가 있는 등 파리선언 이후, 원조효과의 증진 을 위한 공동의 국별 지원전략 수립 및 공동 평가의 필요성이 증대하고 있다. 즉, 수원국의 주인의식과 수원국 · 공여국간 공동책임성 (mutual accountability)을 강화하는 수단으 로서 수원국의 평가 능력 개발(evaluation capacity building)이 시급한 과제로 부각되 고 있는 것으로 파악된다.

- DAC 회원국의 원조효과 공동평가 논의 동향 을 면밀하게 분석하고, $\mathrm{DAC}$ 의 평가기준과 지 침 수립 과정에 우리의 참여를 확대하는 동시 에 국제 평가기준을 우리의 평가제도 운용에 적극적으로 적용해야 한다.

- 특히 개발 클러스터 차원에서의 평가의 중요 성이 강조되고 있는 점을 감안하여, 스웨덴이 나 덴마크 등 주요 원조 공여국과의 공동 평 가 작업 발굴 검토 등을 통해 향후 $\mathrm{DAC}$ 가입 전 평가 작업에 대한 선진화 노력을 강화해야 할 것으로 보인다.

- 최근 다자기구 차원의 원조의 효율성 제고를 위해 캐나다(현재 다자원조 $35 \%$ ), 덴마크(현 재 다자원조 $40 \%$ ) 등은 양자 및 다자원조 비 율의 적절성에 대한 검토가 진행 중임을 구두
로 소개한 바, 우리나라도 동 회원국들의 주요 동향을 예의주시할 필요가 있다.

- 아울러 9 개 회원국(프랑스 참가 예정)으로 구성된 다자기구 성과 측정 네트워크 (Multilateral Organizations Performance Assessment Network: MOPAN)가 다자기 구간 협력관계 행태에 대한 연례 보고를 수 행하고 있음을 영국, 캐나다 등이 지적했다.

\section{III. 주요 논의 내용}

\section{1. 원조효과의 공동평가}

\section{가. 파리선언 이행 공동평가 후속 논의(Joint Evaluation follow up to the Paris Declaration)}

- 수원국 주도 국별 평가(country-led country level evaluations)

- 방글라데시, 볼리비아, 말리, 필리핀, 세네갈, 남아공, 스리랑카, 우간다, 베트남, 잠비아 등 10 개국 수원국 주도의 국별 평가(10개 공여국 이 협조)는 공동의 모니터링 활동 및 기타 입 수가능한 지식에 기초하여, 주로 수원국 및 공여국의 행동 변화를 평가한다.

- 발견된 사실의 비교가능성과 취합을 보장하 기 위해 공동의 평가체계(framework)에 따 라 평가를 설계하되, 국별 특성과 관심사항이 
반영될 수 있도록 충분한 유연성이 필요하다.

- 평가는 수원국내에서 관리되고, 수원국 정부 혹은 관심 있는 공여국 및 기타 이해관계자로 구성된 자문그룹(reference group)의 지원을 받는 독립된 기관에 의해 주도되어야 한다.

- 공여국 주도 본부 평가(donor-led $\mathrm{HQ}$ level evaluations)

- 파리선언 이후 원조기관의 정책, 전략, 인센 티브 변화에 대한 검토가 필요하다.

- 발견된 사실의 비교가능성과 취합을 보장하 기 위해 공동의 평가체계(framework)에 따 라 평가를 설계하되, 국별 특성과 관심사항이 반영될 수 있도록 충분한 유연성이 필요하다.

- 평가는 공여국 혹은 수원국을 포함한 이행관 계자를 포괄하는 자문그룹(reference group) 의 지원을 받는 독립된 기관에 의해 관리되어 야 한다. (베트남과 덴마크가 공동 의장)

- 참가국은 덴마크, 핀란드, 프랑스, 독일, 룩셈 부르크, 네덜란드, 뉴질랜드, UK, UNDP 등 이다.(미국과 일본은 불참)

- 중장기 주제별 연구 계획(medium to longterm programme of thematic studies) - 공동의 평가체계와 관련된 다양한 출처로부 터의 발견 사항들을 평가해야 한다.

- 업무의 중복을 피하기 위해 파리선언 모니터 링 Joint Venture와의 조정이 필요하다.
- 종합보고(synthesis report)

- 중장기 주제별 연구 계획, 수원국 평가 및 공 여국 평가 결과 발견사항 및 교훈점을 종합하 여 2008년 아크라 고위급 포럼에 제출할 예 정이다.

\section{나. GBS 공동평가 후속점검(Follow up to the Joint Evaluation of General Budget Support)}

- GBS Report(The Joint Evaluation of General Budget Support : 1994-2004)는 24 개 공여국과 7 개 파트너 국가(부르키나파 소, 모잠비크, 말라위, 루안다, 우간다, 니카라 과, 베트남)를 대상으로 한 광범위한 평가이 며, 2006년 5월 발간되었다.

- GBS 평가 후속 모니터링을 주도하고 있는 영 국은 관계 공여국 및 수원국에 배포할 설문안 을 제출하였다.

- 동 설문 분석 결과는 모니터링 보고서로 제작 되어 차기 회의에서 논의할 예정이다.

\section{다. 방글라데시 국별지원 공동 평가}

- 세계은행(WB)은 $\mathrm{ADB}, \mathrm{DFID}$, 일본(동 4 개 기 관 및 국가가 대방글라데시 원조 총액의 $80 \%$ 차지) 등과 공동으로 추진중인 방글라데시 국 별 지원 공동평가 사업의 진전 현황을 보고하 
면서, 타 회원국의 지원과 자문을 요청했다.

\section{2. 평가 능력개발(Evaluation Capacity Development)}

a 평가 능력개발의 일환으로 실시된 베트남-호 주 모니터링·평가 강화 프로젝트(VAMESP) 가 소개되었다.

- 3년간 진행중인 베트남의 평가능력개발 제도 및 활동 내역, 교훈 및 향후 추진 방향 등

- 사무국은 2006 년에 실시된 회원국의 평가능 력개발 현황 조사 결과를 상기시키며, 향후 평 가능력개발 사업을 주도할 task force에 관심 있는 국가들의 참여를 요망했다.

\section{3. 변화하는 개발 원 조 환경과 평가} (Evaluation in a Changing Aid and Development Context)

- 빈곤완화전략의 채택, 공동의 지원 전략 수립, 신흥 공여국의 등장, 파리선언 등, 변화된 개 발원조 환경에 따라, 원조효과 평가를 위한 공 동의 국별원조전략 수립 및 공동평가가 필요 하며, 이를 촉진하기 위해 개발 평가네트워크 의 역할이 중요하다는데 참가국들이 의견을 같이 하였다.

- 이에 따라 향후 회의에서 구체적으로 재론키 로 하였다.

\section{4. 평가 기준 및 규범}

\section{가. 평가의 질적 기준 적용}

- 2006. 3월 제4차 개발평가네트워크 회의에서 향후 3 년간 시험 적용기간을 갖기로 승인된 평가의 질적 기준(DAC Evaluation Quality Standards)에 대해, 회원국들의 의견을 종합 하여 향후 워크샵을 개최할 예정이다.

\section{나. 파급효과 평가(Impact Evaluation)}

- 파급효과 평가의 기본 개념과 기법 등을 정립 하기 위해 구성된 task force인 파급효과 평가 네트워크(NONIE)의 워크샵이 지난 2007. 5. $24 \sim 5.25$ 간 헤이그에서 개최되어 논의에 상 당한 진전이 있었으며, 2007년 10월중 워싱턴 에서 $\mathrm{WB}$ 주재로 후속 워크샵을 개최할 예정 이다.

다. 분쟁예방 및 평화구축 (CPPB) 평가 지침 의 개발

- 노르웨이는 $\mathrm{DAC}$ 개발평가네트워크와 분쟁평 화개발협력(CPDC) 네트워크 합동으로 개발한 분쟁예방 및 평화구축 활동 평가 지침 초안을 회원국 의견을 수렴하여 2007년 10월까지 확 정하고, 2007년부터 2008년까지 최소 1년간 시험 적용기간을 거칠 예정임을 보고하였다. 
라. 세계 및 지역 파트너쉽 사업(GRPPs)의 평가

- 세계은행은 독립평가그룹(IEG)이 지난 2007 년 1월 발간한 세계 및 지역 파트너쉽 사업 평 가 보고서(Global and Regional Partnership Program Evaluation Sourcebook)의 주요 내용에 대해 발표하였다.

마. 세계식량계획 평가 기능 동료심사 (Professional Peer Review of the Evaluation Function of the World Food Programme)

- $\mathrm{WFP}$ 의 요청에 따라, UNDP와 UNICEP에 이어, 세번째 다자기구 평가 작업이 추진중이 다. 2007.1월 SIDA가 $\mathrm{WFP}$ 의 평가부서 $\mathrm{OEDE}$ 와 체결한 약정에 따라, 심사 패널을 주
도하기로 동의하였으며, 2007.5월 9월간 자료 수집을 거쳐, 10 월중 보고서 초안이 제 출될 예정이다.

바. HIV/AIDS 평가 작업 현황 및 향후 협력 방안

- 개발평가네트워크 의장은 세계기금(Global Fund), AIDS 구호를 위한 미대통령 긴급프로 그 램 (US President's Emergency Programme for AIDS Relief), 백신 · 면역을 위한 세계연대(Global Alliance for Vaccines and Immunization) 등을 중심으로 실시되었 거나, 실시 예정인 평가 작업을 소개했다. 아 울러 개발평가네트웍 차원의 동 분야 평가 협 력 방안을 강구하기를 희망했다.

[자료: 주오이시디대표부] 